\title{
Amitriptyline Supersensitizes a Central Cholinergic Mechanism
}

\author{
Steven C. Dilsaver, R. Michael Snider, and Norman E. Alessi
}

The withdrawal of tricyclic antidepressants produces symptoms characteristic of cholinergic overdrive states. The authors previously proposed that these states are the consequence of the pharmacological induction of cholinergic system supersensitivity by chronic treatment with antidepressants, combined with a reduction in the plasma level of a competitive muscarinic receptor antagonist when the dose of a tricyclic is decreased. This is consistent with the facts that all tricyclic antidepressants are antimuscarinic agents and that classical antimuscarinic compounds, such as scopolamine, up-regulate and supersensitize muscarinic cholinergic systems. The authors present evidence that chronic treatment with amitriptyline supersensitizes a central cholinergic mechanism. Core body temperature is subject to influence by a central (hypothalamic) muscarinic mechanism, which is rendered supersensitive to cholinomimetic challenge by treatment with scopolamine. The authors telemetrically measured the hypothermic responses of adult male rats to various doses of the muscarinic agonist oxotremorine before and in the course of chronic treatment with amitriptyline. Treatment with amitriptyline resulted in marked enhancement of the cholinomimetic-induced hypothermia. Methylscopolamine nitrate, a peripherally active antimuscarinic agent, did not block the hypothermic response to oxotremorine, whereas scopolamine, a centrally active antimuscarinic compound, did. This study indicates that the chronic administration of amitriptyline can produce supersensitivity of a central muscarinic cholinergic mechanism. Clinical and theoretical implications of this finding are discussed.

\section{Introduction}

Many of the symptoms that commonly follow the discontinuation of tricyclic antidepressants (TCAs) suggest withdrawal-induced cholinergic overdrive (Dilsaver et al. 1983a; Dilsaver and Greden 1984). Evidence supporting this includes observations that (1) anticholinesterases produce similar symptoms (Dilsaver 1986a,b); (2) TCA withdrawal symptoms respond to antimuscarinic agents (Dilsaver et al. 1983b); (3) TCAs competitively displace muscarinic acetylcholine receptor ( $\mathrm{mAchR}$ ) radioligands in binding experiments (Snyder and Yamamura 1977) and produce physiological and biochemical effects indic-

From the Department of Psychiatry, Mental Health Research Institute (S.C.D., N.E.A.), and the Neuroscience Laboratory (R.M.S.), University of Michigan, Ann Arbor, MI.

Address reprint requests to Dr. Steven C. Dilsaver, Department of Psychiatry, Mental Health Research Institute, University of Michigan, 205 Washtenaw Place, Ann Arbor, MI 48109-1687.

Received January 3, 1986; revised September 15, 1986.

Presented at the 41st Annual Meeting of the Society of Biological Psychiatry, Washington, D.C., May 7-11, 1986. 
ative of mAchR blockade (Atkinson and Landinsky 1972; Richelson and Dininetz-Romero 1977; Blackwell et al. 1978; Szabadi et al. 1980); and (4) anticholinergic agents upregulate and supersensitize cholinergic networks in rodents (Dilsaver 1986c).

Body temperature is subject to regulation by central (hypothalamic) cholinergic mechanisms (Lomax et al. 1964; Lomax and Jenden 1966), which are supersensitized by mAchR blockade in rats (Jaffe and Sharpless 1968; Friedman et al. 1969). We tested the hypothesis that chronic treatment with a TCA produces cholinergic system supersensitivity by measuring the hypothermic response to the centrally active cholinomimetic oxotremorine $(\mathrm{OXO})$, before and after chronic treatment with amitriptyline (AMI).

\section{Methods}

\section{Temperature Measurement}

Thermosensors (Mini-Mitter Co., Sun River, OR) were surgically implanted into the peritoneal cavity of rats. These devices emit Hertzian waves at a rate proportional to temperature. A transistor radio set to an AM frequency served as a receiver. Time to emit 25 sounds or "clicks" was measured using a digital display stopwatch. This measure was converted to temperature using a linear regression equation that was derived by measuring the emission rate of the thermosensors at three temperatures in a temperaturecontrolled water bath. This procedure is sensitive to a $0.1^{\circ} \mathrm{C}$ change in temperature (ToccoBradley et al. 1985).

\section{Oxotremorine Challenge}

All OXO challenges were conducted at the same time of day, $12 \mathrm{hr}$ after the evening dose of AMI. Methylscopolamine nitrate $(1 \mathrm{mg} / \mathrm{kg}$, i.p.) was administered $30 \mathrm{~min}$ prior to the i.p. injection of OXO to block its peripheral effects. Temperature (i.e., time to the 25th "click") was measured immediately prior to and 30 min after injecting methylscopolamine, which alone did not affect temperature in 31 trials. Baseline temperature was defined as the average of the pre- and postmethylscopolamine nitrate measurements. OXO was given immediately after the 30 -min postmethylscopolamine nitrate temperature measurement. Temperature was recorded every $15 \mathrm{~min}$ for $120 \mathrm{~min}$.

\section{Pharmaceuticals}

OXO, methylscopolamine nitrate, scopolamine hydrobromide, and amitriptyline hydrochloride were purchased from Sigma Chemical Company (St. Louis, MO). Doses of OXO refer to the base. Doses of the other drugs were expressed as the salt form. All drugs were given intraperitoneally on a milligram per kilogram basis.

\section{Experimental Design}

Experiment 1. Figure 1 presents the course of Experiment 1. The experiment was divided into four phases. In Phase I (implantation), thermosensors were implanted in 15 male adult Sprague-Dawley rats, and they were allowed 5 days to recover. During Phase II, the baseline hypothermic response to OXO $(0.05,0.10,0.25,1.0$, and $2.5 \mathrm{mg} / \mathrm{kg})$ was recorded in three groups of five animals each, as shown in Figure 1. Throughout 


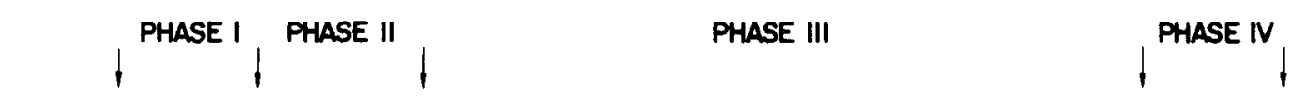

Dars

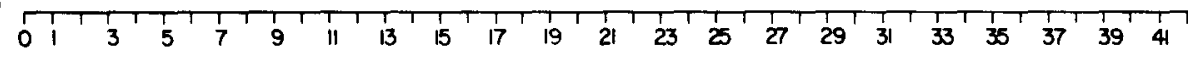

$\underset{(10 \mathrm{mg} / \mathrm{kg}, \text { b.i.d. })}{A M I} \stackrel{A M I}{(20 \mathrm{mg} / \mathrm{kg}, \text { b.i.d. })}$

OXO

CHALENGES

GROUP

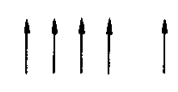

DAY 5 DAY 6 DAY 7 DAY 8 DAY

\begin{tabular}{r|c|c|c|c|c|}
\hline DAY5 DAY 6 DAY7 DAY B DAYD \\
\hline I (n-5) & 0.05 & 0.25 & 0.10 & 1.0 & 2.5 \\
\hline II (n-5) & 0.1 & 0.05 & 0.25 & 1.0 & 2.5 \\
\hline III (n=5) & 0.25 & 0.10 & 0.05 & 1.0 & 2.5 \\
\hline
\end{tabular}

Between doys 23 and 27 (12-16 doys

of treotiment) each animal retaining

a functional thermosensor received
challenge with $0 \times 0,0.1$, and 0.25 .
$0.125 \mathrm{mg} / \mathrm{kg}$ $(n=9)$

Figure 1. The course of Experiment 1. See the Methods section for details.

Phase III, animals were treated with AMI (10 mg/kg, i.p., twice daily) for 16 days. The animals were rechallenged with $\mathrm{OXO}, 0.05,0.1$, or $0.25 \mathrm{mg} / \mathrm{kg}$, between days 12 and 16 of treatment with AMI. These data were compared to the pre-AMI response to various doses of OXO. In Phase IV, 9 animals received AMI $(10 \mathrm{mg} / \mathrm{kg})$ for an additional 10 days. They then received AMI, $20 \mathrm{mg} / \mathrm{kg}$ for 5 more days prior to receiving a challenge with $\mathrm{OXO}$ at $0.125 \mathrm{mg} / \mathrm{kg}$.

Experiment 2. Two groups of animals were challenged with $\mathrm{OXO}, 1 \mathrm{mg} / \mathrm{kg}$, i.p., prior to starting a course of AMI, $10 \mathrm{mg} / \mathrm{kg}$ twice daily for 2 days and $15 \mathrm{mg} / \mathrm{kg}$ twice daily for 5 days $(n=5)$, or saline $(n=4)$. The maximum hypothermic response and decrease in temperature over time at baseline and after treatment were compared within and between groups.

Experiment 3. Eleven animals in Experiment 1 received AMl $10 \mathrm{mg} / \mathrm{kg}$, i.p., for 17 days. These animals then received scopolamine hydrobromide, $2 \mathrm{mg} / \mathrm{kg}$, i.p., as a pretreatment in lieu of methylscopolamine nitrate in order to assess whether a peripheral or central mechanism underlies OXO-induced hypothermia.

\section{Statistical Analysis}

Data were analyzed using (1) Analysis of Variance (ANOVA) with repeated measures to assess the significance of differences between phases due to a drug effect (i.e., preand posttreatment), (2) two-sample $t$-tests for comparing sample means, and (3) paired $t$-tests to assess the significance of changes in the mean maximum hypothermic response and the mean hypothermic response over all eight time points within a sample, before and after the chronic administration of AMI. Calculation of confidence intervals was used 
to determine whether or not the mean change in core temperature produced by $\mathrm{OXO}(2.5$ $\mathrm{mg} / \mathrm{kg}$ ) after pretreatment with scopolamine hydrobromide in Experiment 3 differed significantly from the condition of pretreatment with methylscopolamine nitrate at specific points in time after the injection of OXO and whether or not the mean effect (average response to $\mathrm{OXO}$ over all eight time points) differed.

\section{Results}

\section{Experiment 1}

OXO produced dose-dependent hypothermia prior to AMI treatment. This was evidenced by significant differences in the magnitude of the hypothermic responses over time to OXO: 0.1 versus $1.0 \mathrm{mg} / \mathrm{kg}, p<0.01 ; 1 \mathrm{mg} / \mathrm{kg}$ versus $2.5 \mathrm{mg} / \mathrm{kg}, p<0.05$ (ANOVA with repeated measures). Table 1 summarizes the responsiveness to $\mathrm{OXO}$ at $0.05,0.10$, and $0.25 \mathrm{mg} / \mathrm{kg}$ before and after treatment with AMI, $10 \mathrm{mg} / \mathrm{kg}$, i.p., twice daily for 12-16 days. Table 2 presents the corresponding data on the responsiveness to $\mathrm{OXO}$ at 1.0 and $2.5 \mathrm{mg} / \mathrm{kg}$, i.p. The 9 animals that were rechallenged with $\mathrm{OXO}$ at $0.05 \mathrm{mg} / \mathrm{kg}$ after 12-16 days of treatment with AMI exhibited significant enhancement of the hypothermic response $(p<0.05)$. The 10 animals rechallenged with $O X O$ at $0.1 \mathrm{mg} / \mathrm{kg}$ after 12-16 days of AMI treatment showed enhancement of the hypothermic response $(p<0.02)$. OXO at $0.25 \mathrm{mg} / \mathrm{kg}$ also produced increased hypothermia relative to the pretreatment phase $(p<0.0001, \mathrm{n}=11)$ posttreatment. Figure 2 pictorially presents the difference in the hypothermic response to OXO at $0.10 \mathrm{mg} / \mathrm{kg}$ before and after treatment with AMI. Animals treated with AMI (10 mg/kg for 26 days, followed by 20 $\mathrm{mg} / \mathrm{kg}$ for 5 additional days) had a mean maximum decrease in temperature of $1.51 \pm 0.19^{\circ} \mathrm{C}$ (SEM) when given OXO at $0.125 \mathrm{mg} / \mathrm{kg}$. Change in temperature over time in response to OXO at $0.125 \mathrm{mg} / \mathrm{kg}$ was actually greater after treatment with AMI than it was in response to OXO at $2.5 \mathrm{mg} / \mathrm{kg}$ at baseline ( $p<0.02$, ANOVA with repeated mcasurcs). Table 3 summarizes these data, and Figure 3 illustrates the general relationship between dose of OXO and hypothermic response before and after treatment with AMI.

\section{Experiment 2}

The maximum decrease in temperature and change in temperature over time did not change in the saline-treated sample $(n=4)$. The AMI-treated sample demonstrated a significantly greater maximum decrcase in temperature $\left[1.57 \pm 0.15^{\circ} \mathrm{C}\right.$ (SEM) versus $0.64 \pm 0.12^{\circ} \mathrm{C}, p<0.05$, two-sample $t$-test] compared to the saline-treated sample after, but not before, the 7 days of treatment. Furthermore, the AMI group $(n=5)$ exhibited a significant increase in its maximum hypothermic response of $1.2 \pm 0.34^{\circ} \mathrm{C}$ (SEM) $(p<0.05$, paired $t$-test) and trends toward a significant decrease in temperature over all 8 points in time ( $p<0.06$, ANOVA with repeated measures) compared to its pretreatment phase. The results of this experiment are depicted in Figure 4.

\section{Experiment 3}

Scopolamine markedly blunted the hypothermic effects of OXO. The mean maximal decrease in temperature in response to $\mathrm{OXO}$ at $2.5 \mathrm{mg} / \mathrm{kg}$ after pretreatment with scopolamine $(2 \mathrm{mg} / \mathrm{kg}$, i.p. $)$ was $0.17 \pm 0.08^{\circ} \mathrm{C}(\mathrm{SEM})(\mathrm{n}=11)$ in animals that were treated 


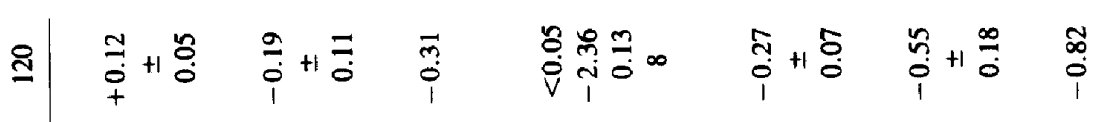

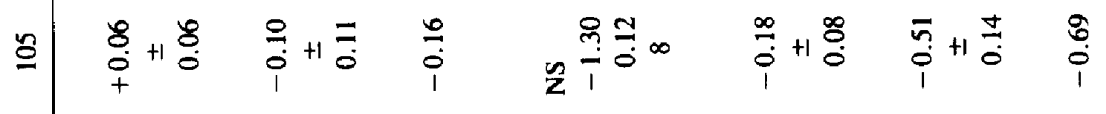

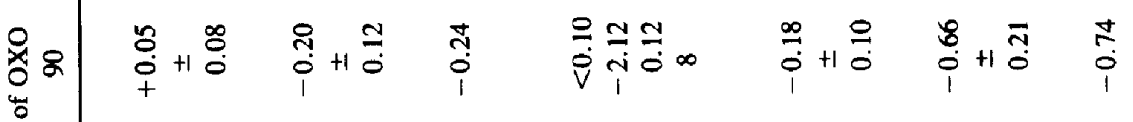

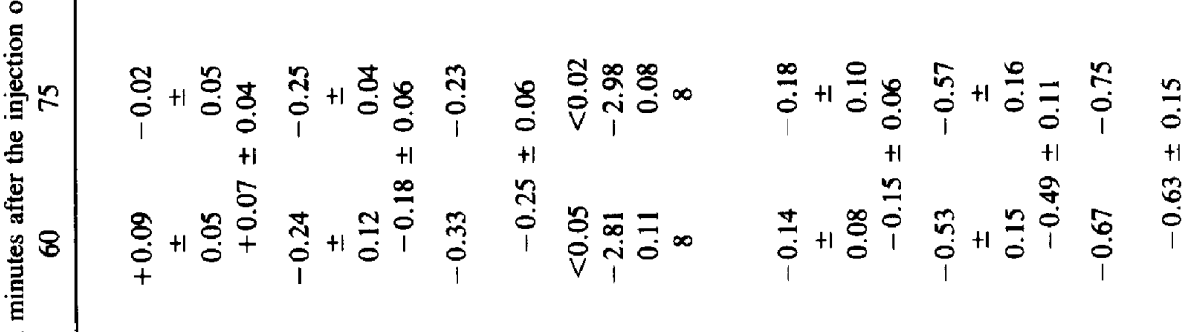

皇

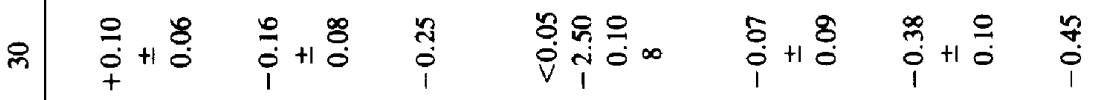

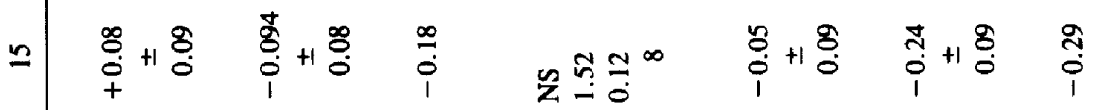
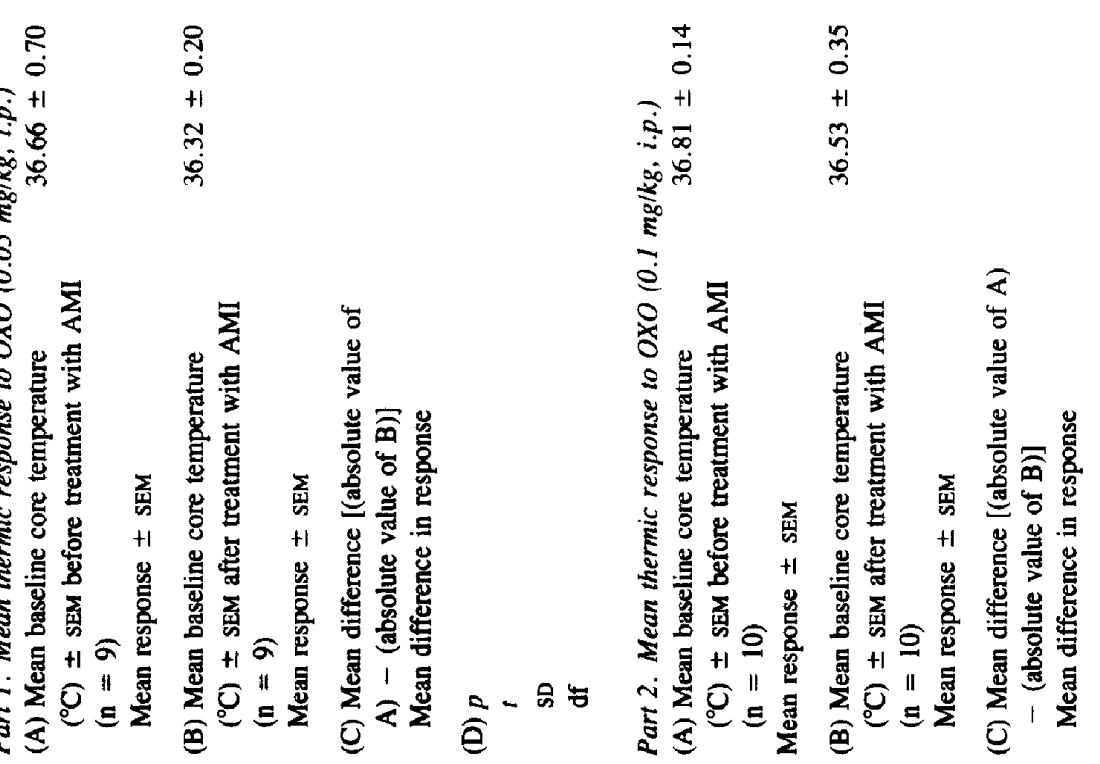


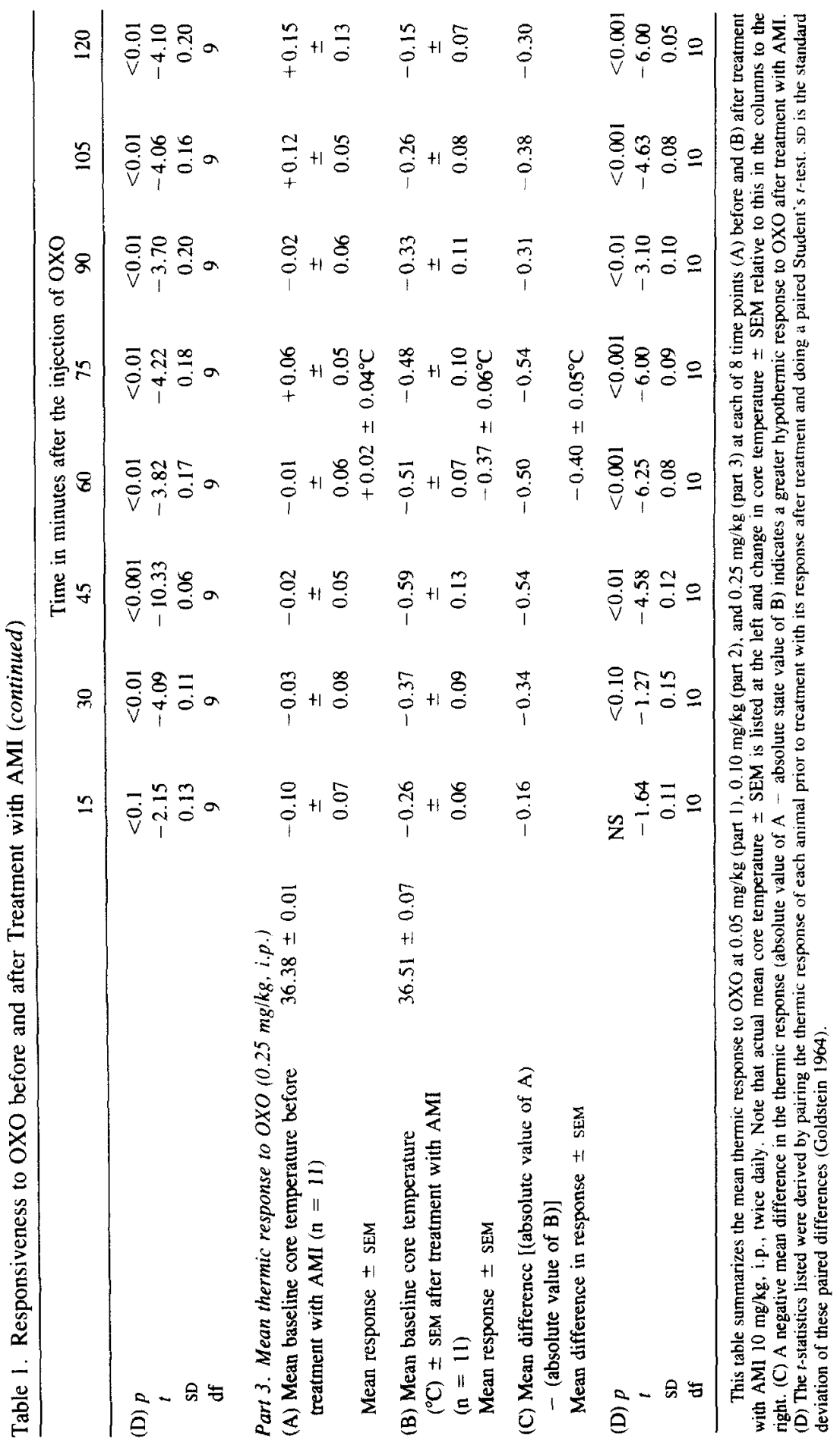


Table 2. Thermic Response to OXO

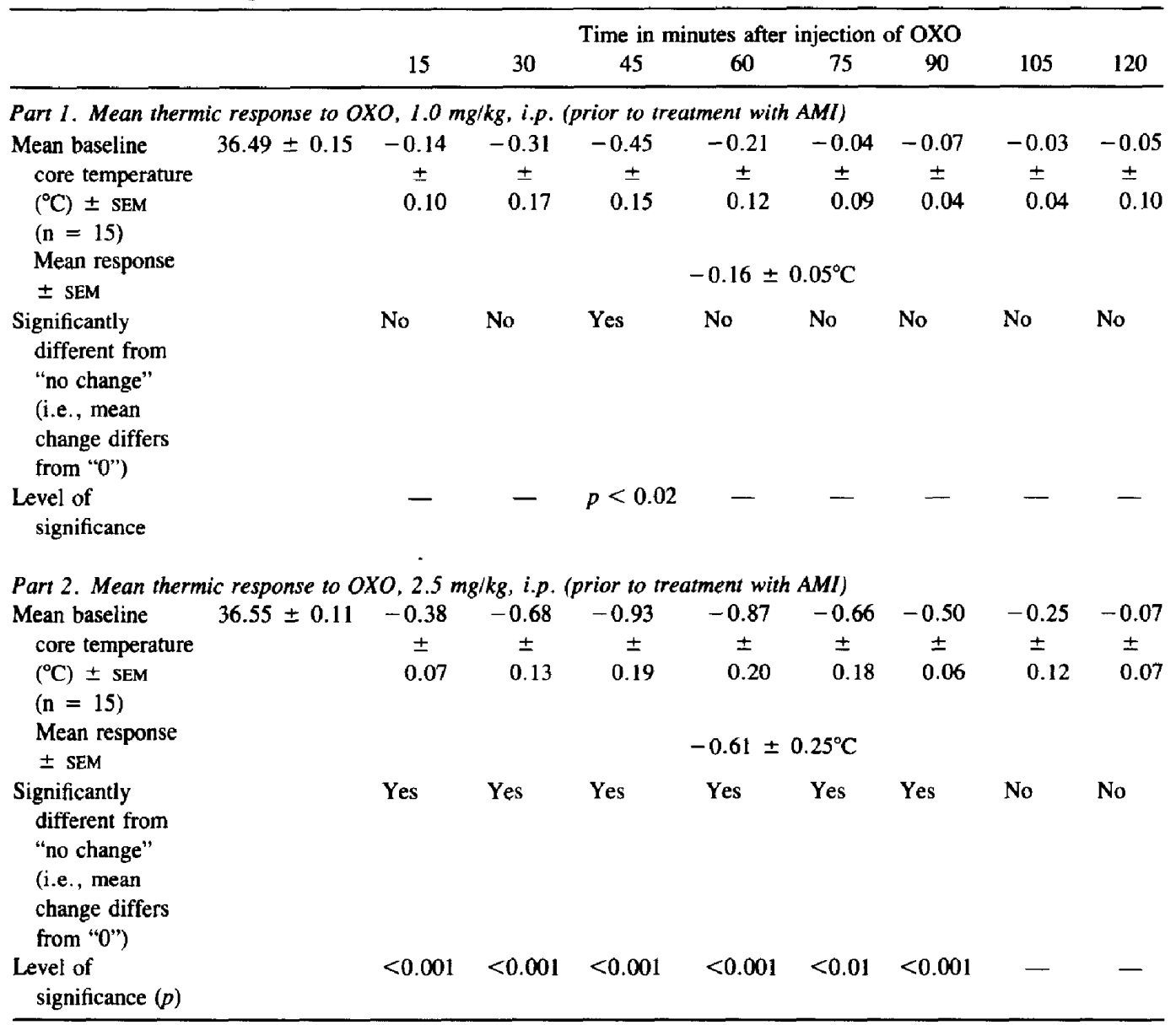

Part 1 summarizes data on the thermic responsiveness of 15 rats to $O X O$ at $1.0 \mathrm{mg} / \mathrm{kg}$, i.p., prior to treatment with AMI. The mean response was significantly different (as determined by calculation of confidence intervals) from " 0 " (i.e., no change) at only one point. Part 2 presents the corresponding data on the responsiveness of the sample to $O X O$ at $2.5 \mathrm{mg} / \mathrm{kg}, \mathrm{i} . \mathrm{p}$.

with AMI at $10 \mathrm{mg} / \mathrm{kg}$, i.p., twice daily for 17 days (NS, 95\% confidence limits $=+0.01$ to $-0.35^{\circ} \mathrm{C}$ ), and the average change in temperature over time (i.e., the mean of all 11 animals over all 8 points) was $0.11 \pm 0.03^{\circ} \mathrm{C}$ (SEM) $(99 \%$ confidence limits $=-0.01$ to $\left.-0.21^{\circ} \mathrm{C}\right)$ compared to $-0.54 \pm 11^{\circ} \mathrm{C}$ (SEM) $(99 \%$ confidence limits $=-0.213$ to $-0.87^{\circ} \mathrm{C}$ ) when treated with methylscopolamine. Thus, the difference in responsiveness to $\mathrm{OXO}$ at $2.5 \mathrm{mg} / \mathrm{kg}$ under the condition of pretreatment with scopolamine and methylscopolamine differed at the 0.01 level. The results of this experiment are presented in Figure 5.

\section{Discussion}

Maximum decrease in core temperature, changes in temperature over time, and change in core temperature at $\mathbf{8}$ points in time after the injection of OXO were used as dependent variables in evaluating the effects of chronic treatment with AMI on a muscarinic cho- 


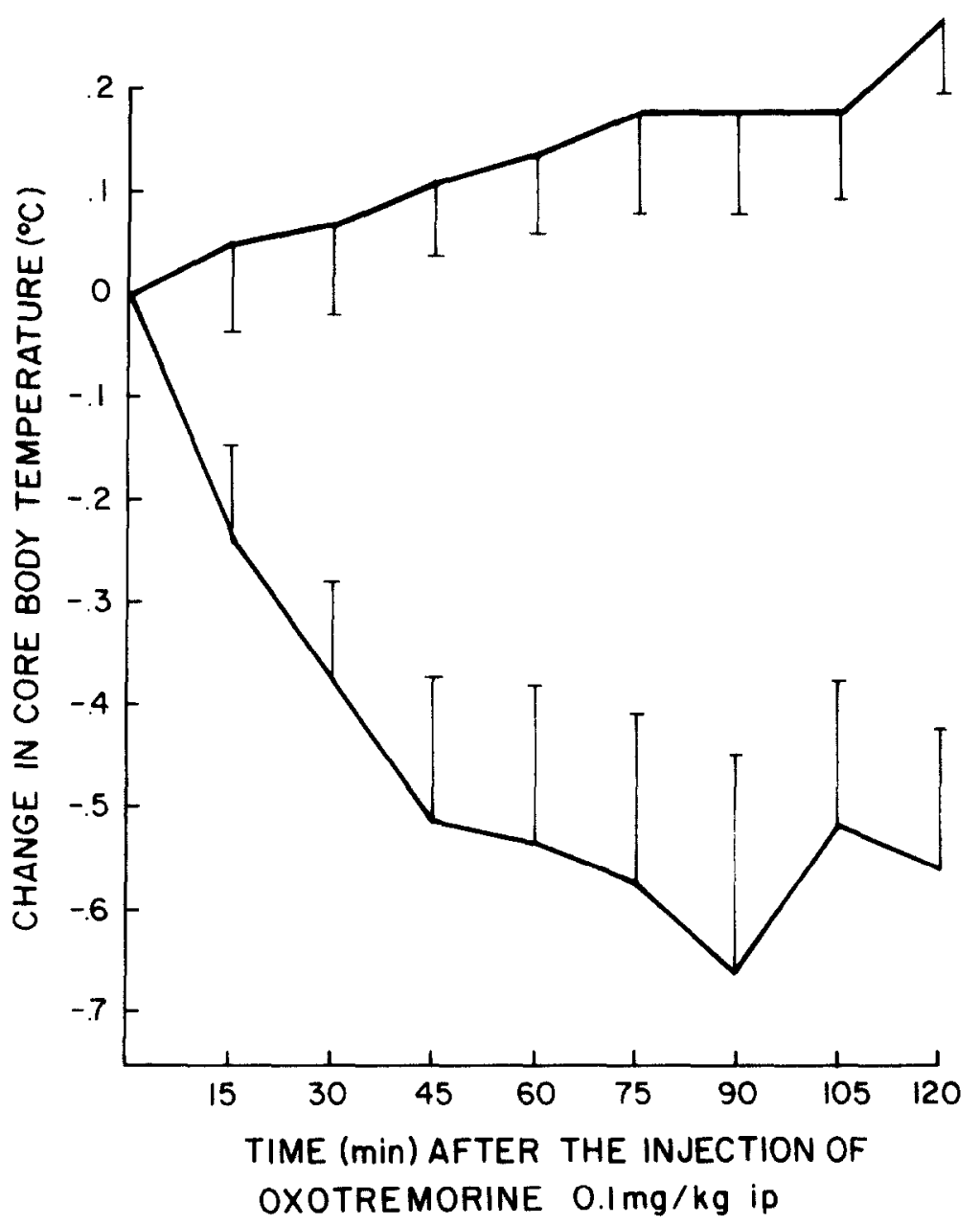

Figure 2. The mean difference \pm SEM in the hypothermic response to $O X O(0.10 \mathrm{mg} / \mathrm{kg}$, i.p. $)$ prior to and after treatment with AMI (10 $\mathrm{mg} / \mathrm{kg}$, i.p. twice daily for $12-16$ days). The mean difference is significant at $p<0.02$. Furthermore, there was a significant difference in the direction predicted by the hypothesis that AMI enhances sensitivity to the hypothermic effects at 7 of 8 points in time.

linergic system. The data indicate that (1) saline injections do not alter the hypothermic response to $\mathrm{OXO}$; (2) treatment with $\mathrm{AMI}$ enhanced the hypothermic response to OXO $(0.05,0.1$, and $0.25 \mathrm{mg} / \mathrm{kg})$ relative to the pretreatment baseline; (3) scopolamine $(2.0$ $\mathrm{mg} / \mathrm{kg})$, but not methylscopolamine nitrate, blocks the OXO $(2.5 \mathrm{mg} / \mathrm{kg})$ induced temperature decrease, implicating a central cholinergic mechanism; and (4) AMI induces central cholinergic system supersensitivity. These results support the hypothesis that cholinergic overdrive is involved in the pathophysiology of some TCA withdrawal phenomena. The observation that 21 days of treatment with desipramine produces supersensitivity of the iris to pilocarpine (i.e., results in a greater miotic response) relative to the 
Table 3. Within-Animal Comparison of the Thermic Response to OXO $(0.125 \mathrm{mg} / \mathrm{kg}$, i.p. $)$ after Treatment with AMI to the Thermic Response to OXO (2.5 mg/kg, i.p.) prior to Treatment with AMI

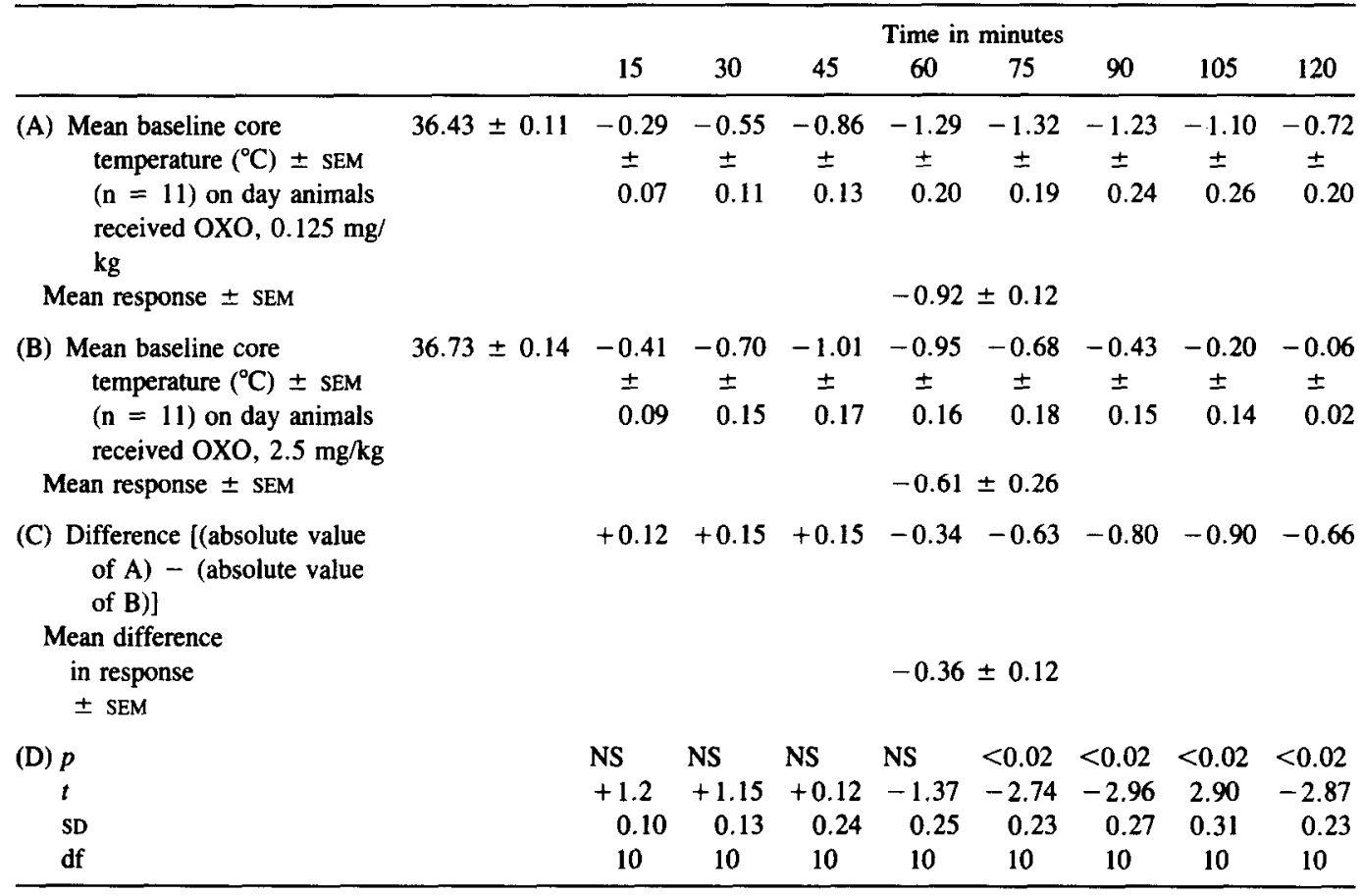

This table compares the mean hypothermic response at each of 8 time points after the injection of $\mathrm{OXO}$ at $2.5 \mathrm{mg} / \mathrm{kg}$ at bascline and $0.125 \mathrm{mg} / \mathrm{kg}$ after chronic (31 days) treatment with AMI. All animals received AMI (10 mg/kg, i.p.) twice daily for 26 days, followed by $20 \mathrm{mg} / \mathrm{kg}$ was a more potent inducer of hypothermia after chronic treatment than was $2.5 \mathrm{mg} / \mathrm{kg}$ at baseline.

pretreatment baseline in normal human subjects also supports this conclusion (Dilsaver and Greden 1983).

Nomura et al. $(1982 a, b)$ reported corroborative findings in rat myocardium using desipramine at $10 \mathrm{mg} / \mathrm{kg}$ twice daily for 10 days. This regimen was associated with enhancement of the negative inotropic effects and an increase in the acetylcholine-mediated augmentation of the activity of ornithine carboxylase. These investigators also found an increased density of $m A c h R$ radioligand binding sites in this preparation following treatment with DMI. Rehavi et al. (1980) and Goldman and Erickson (1983) have similarly documented that 10-21 days of treatment with AMI results in up-regulation of mAchRs in mouse and rat brain, respectively.

An array of evidence suggests that the pathophysiology of depression involves supersensitivity of central muscarinic cholinergic mechanisms (Dilsaver 1986b). Pharmacological agents that supersensitize cholinergic neurons may be useful in modeling aspects of the pathophysiology of depressive disorders. Measures useful in describing the neurobiology of these illnesses can be classified as being (1) phenomenological or behavioral, (2) physiological, (3) biochemical, and (4) receptor binding variables (Dilsaver 1986a). Cholinergic manipulations change variables in each of these classes. Many of these alterations are consistent with the hypothesis that hyperactivity or supersensitivity of 


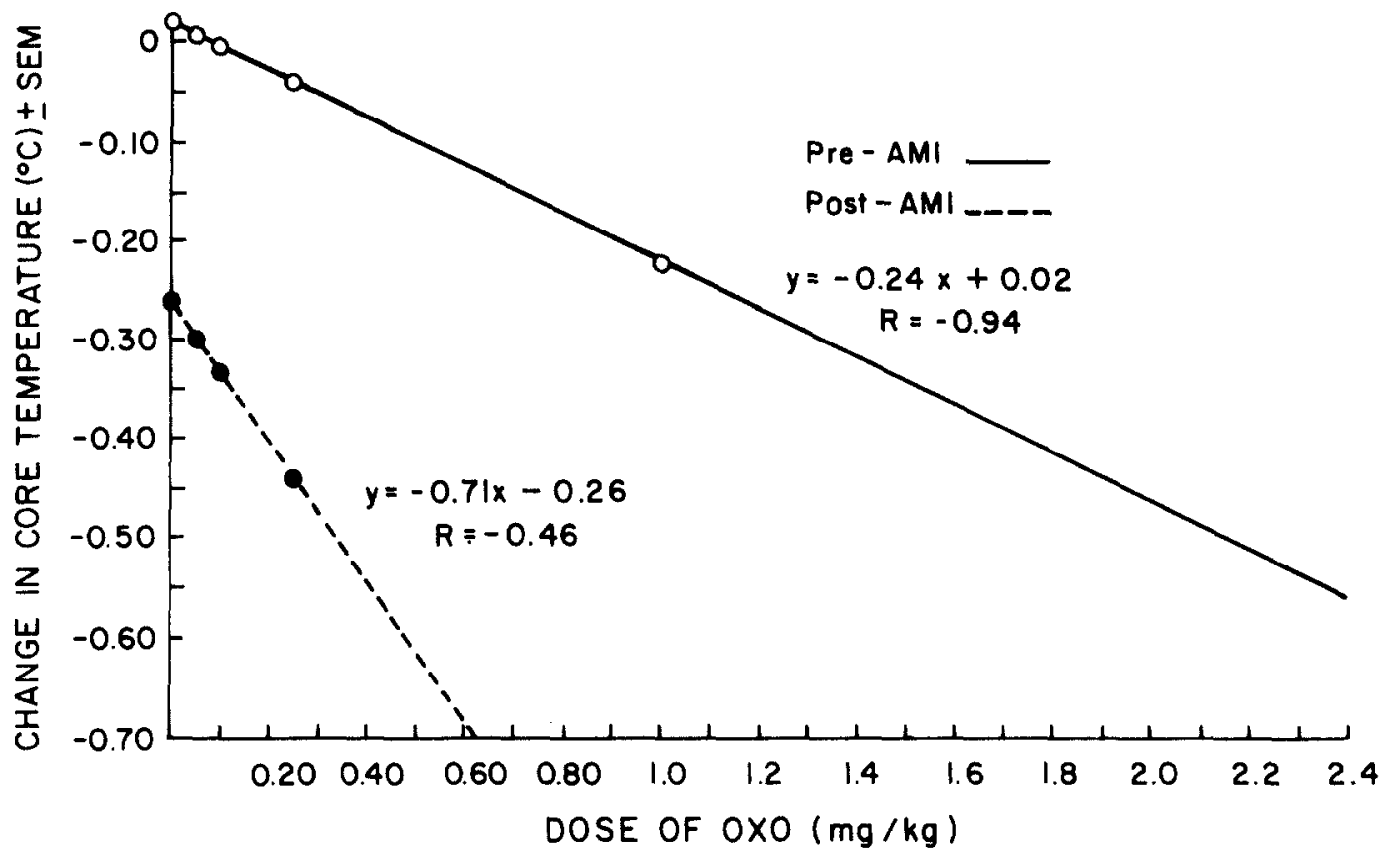

Figure 3. This illustrates a shift in the dose-response curve for induction of hypothermia by OXO to the left after treatment with AMI at $10 \mathrm{mg} / \mathrm{kg}$, i.p. twice daily for $12-16$ days. The mean responses of 15 animals to OXO at $0.05,0.10,0.25,1.0$, and $2.5 \mathrm{mg} / \mathrm{kg}$, i.p., prior to TCA treatment entered into calculation of the regression equation characterizing sensitivity at baseline. Responsiveness to $\mathrm{OXO}$ at $0.05,0.10$, and $0.25 \mathrm{mg} / \mathrm{kg}$ was used to obtain the posttreatment equation.

cholinergic systems are involved in the pathogenesis of depressive disorders. For instance, administration of scopolamine to normal human subjects for three consecutive mornings resulted in shortened REM latency and increased REM density on the night after the dose was held on the fourth morning. The polysomnograms of these subjects were indistinguishable from those of patients with primary depression. Another phenomenon that may be related to the capacity of TCAs to render cholinergic systems supersensitive is the significant increase in the postdexamethasone plasma cortisol concentration and frequency of positive Dexamethasone Suppression Test (DST) results during a 14-day withdrawal phase (Dilsaver and Greden 1985). Finally, Kelwala (1984) reported that depressed patients demonstrate increased miosis in response to pilocarpine compared to normal and nonaffectively ill psychiatric control subjects. The capacity of desipramine to produce this effect in depressed patients (Dilsaver and Greden 1983) may be another illustration of the way in which antimuscarinic agents, including TCAs, may be useful in modeling aspects of the pathophysiology of depression related to supersensitivity of the cholinergic systems.

In conclusion, treatment with AMI resulted in supersensitization of a central cholinergic mechanism involved in thermoregulation. This is consistent with the hypotheses that TCA withdrawal symptoms may be due to withdrawal-induced cholinergic overdrive (Dilsaver 


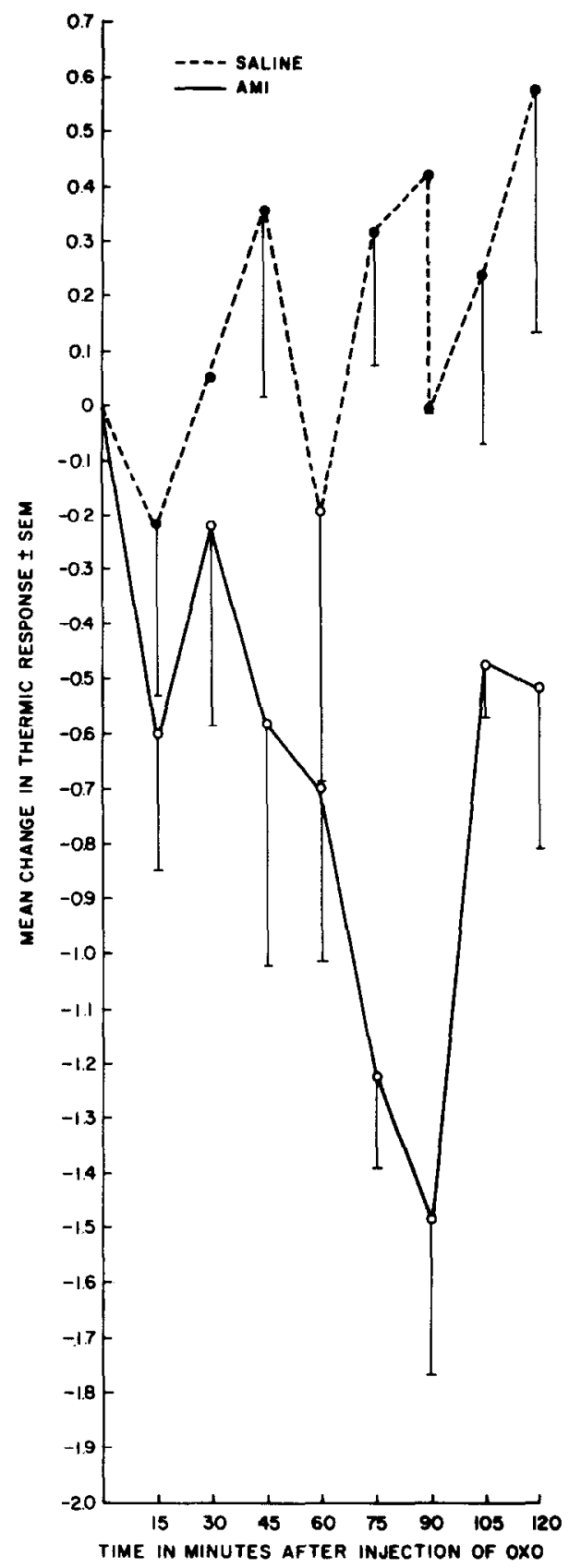

Figure 4. The change in the thermic response to OXO $(1 \mathrm{mg} / \mathrm{kg}$, i.p. $)$ in rats receiving twice daily i.p. injections of saline $(\mathrm{n}=4)$ or AMI $(15 \mathrm{mg} / \mathrm{kg})$ $(n=5)$. Both samples were challenged with OXO prior to and after saline or AMI administration. The thermic response at a given time point on a particular day is derived from the formula: (core body temperature at that point in time) - (core body temperature prior to the injection of OXO on that day). Change in the thermic response at a given point after treatment with saline or AMI is given by the formula: (thermic response after treatment) - (thermic response prior to treatment). The thermic response of the sample treated with saline did not change significantly, whereas that of the AMI-treated group did.

et al. 1983a; Dilsaver and Greden 1984), and TCAs may be useful for approximating or modeling those aspects of the pathophysiology of depressive disorders related to upregulation and supersensitivity of cholinergic systems (Dilsaver 1986a-c).

Supported in part by Physician Scientist Career Development Award MH 0055301 (Muscarinic Receptor Abnormalities in Affective Illness) (S.C.D.) and NS 20920 (R.M.S.). 


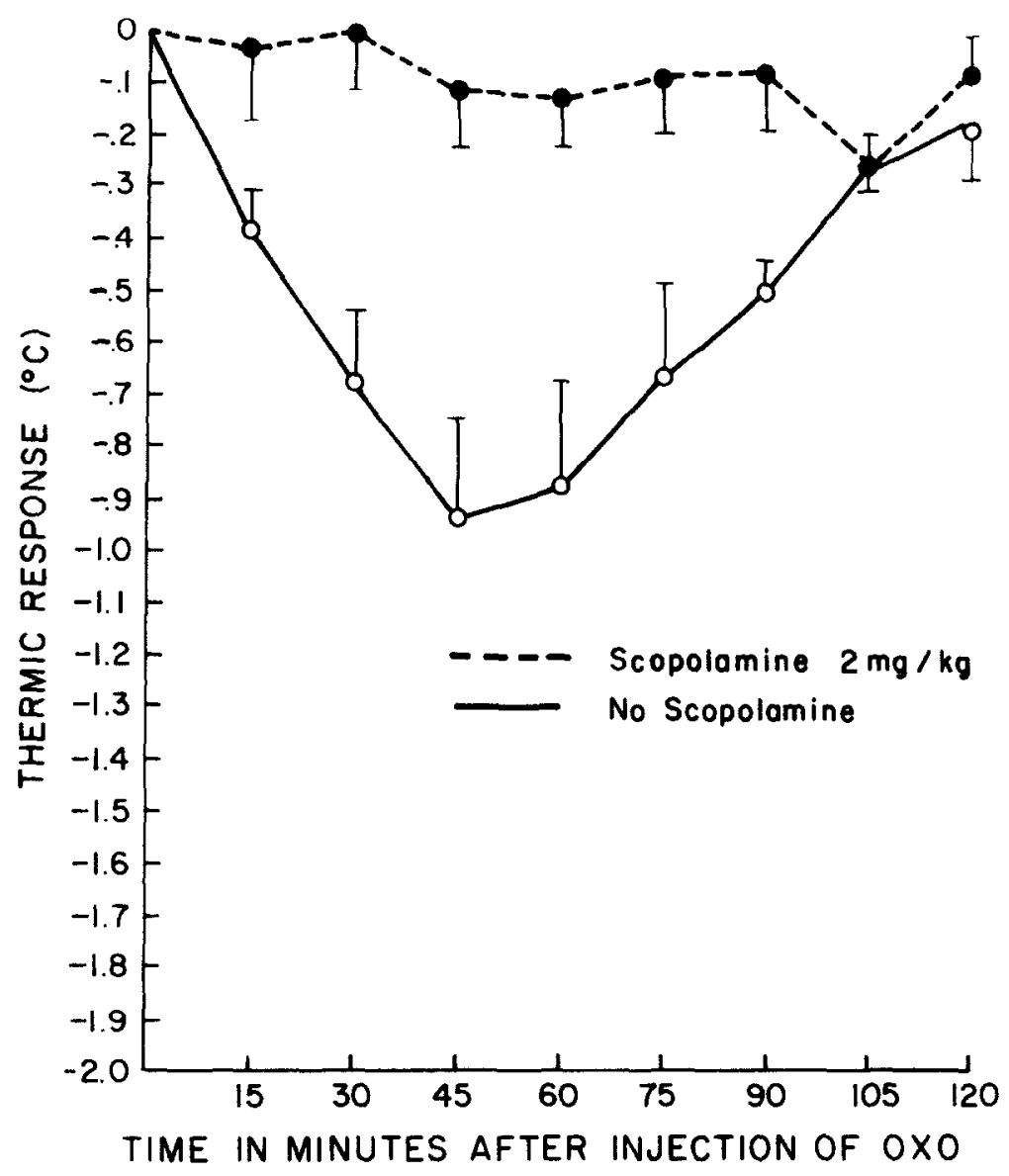

Figure 5. The thermic response of 11 animals to OXO $(2.5 \mathrm{mg} / \mathrm{kg})$ in the presence and absence of scopolamine $(2 \mathrm{mg} / \mathrm{kg}, \mathrm{i} . \mathrm{p}$.). Pretreatment with scopolamine was associated with significant blunting of the hypothermic response $(p<0.01)$.

\section{References}

Atkinson J, Landinsky H (1972): The quantitative study of the anticholinergic action of several tricyclic antidepressants on the rat isolated fundal strip. Br J Pharmacol 45:519-524.

Blackwell B, Stefopoulos A, Enders P, Kuzma R, Adolphe A (1978): Anticholinergic activity of two tricyclic antidepressants. Am J Psychiatry 135:722-724.

Dilsaver SC (1986a): Pharmacologic induction of cholingeric system up-regulation and supersensitivity in affective disorders research. $J$ Clin Psychopharmacol 6:65-74.

Dilsaver SC (1986b): Cholinergic mechanisms in depression. Brain Res Rev 11:285-316.

Dilsaver SC (1986c): Cholinergic mechanisms in affective disorders: Future directions for investigation. Acta Psychiatr Scand (in press).

Dilsaver SC, Greden JF (1983): Antidepressant withdrawal syndromes: Evidence for supersensitivity of the cholinergic system as an etiologic factor. $J$ Clin Psychopharmacol 3:330.

Dilsaver SC, Greden JF (1984): Antidepressant withdrawal phenomena. Biol Psychiatry 19:237-256.

Dilsaver SC, Kronfol Z, Greden JF, Sackellares JC (1983a): Antidepressant withdrawal syndromes: Evidence supporting the cholinergic overdrive hypothesis. J Clin Psychopharmacol 3:157-164. 
Dilsaver SC, Feinberg M, Greden JF (1983b): Antidepressant withdrawal symptoms treated with anticholinergic agents. Am J Psychiatr 140:249-251.

Friedman MJ, Jaffe JH, Sharpless SK (1969): Central nervous system supersensitivity to pilocarpine after withdrawal of chronically administered scopolamine. J Pharmacol Exp Ther 167:45-55.

Gillin JC, Sitaram N, Duncan WC (1979): Muscarinic supersensitivity: A possible model for the sleep disturbance of primary depression? Psychiatry Res 1:17-22.

Goldman ME, Erickson CK (1983): Effects of acute and chronic administration of antidepressant drugs in the central cholinergic nervous system: Comparison with anticholinergic drugs. Neuropharmacology 22:1215-1222.

Jaffe JH, Sharpless SK (1968): Pharmacological denervation supersensitivity in the central nervous system. Res Nerv Ment Dis 46:226-241.

Kelwala S (1984): Enhanced pilocarpine miosis in depressed patients. Presented at the 137th Annual Meeting of the American Psychiatric Association, Los Angeles, CA, May 5-11, NR25.

Lomax P, Jenden DJ (1966): Hypothermia following systematic and intracerebral injection of oxotremorine in the rat. Neuropharmacology 5:353-359.

Lomax P, Foster RF, Kirkpatrick WE (1964): Cholinergic and adrenergic interactions in the thermoregulatory centers of the rat. Brain Res 15:431-438.

Nomura Y, Kajiyama H, Okai K (1982a): Influence of repeated administration of desmethylimipramine on $\beta$-adrenergic and muscarinic cholinergic receptors and ${ }^{45} \mathrm{Ca}^{++}$binding to sarcoplasmic reticulum in the rat heart. $J$ Pharmacol Exp Ther 223:834-840.

Nomura Y, Kajiyama H, Segawa T (1982b): Alteration in sensitivity to isoproterenol and acetylcholine in rat heart after repeated administration of isoproterenol. $J$ Pharmacol Exp Ther 220:441-445.

Nomura Y, Kajiyama A, Segawa T (1983): Possible influence of noradrenalin on $\beta$-adrenergic and muscarinic receptors in rat heart: Effects of 6-hydroxydopamine, isoproterenol and desmethylimipramine. In Segawa T et al. (eds), Molecular Pharmacology of Neurotransmitter Receptors. New York: Raven Press, pp 83-90.

Overstreet DH, Kozar MP, Lynch GS (1973): Reduced hypothermic effects of cholinomimetic agents following chronic anticholinesterase treatment. Neuropharmacology 12:1017-1032.

Rehavi M, Ramot O, Yavetz B, et al (1980): Amitriptyline: Long-term treatment elevates alphaadrenergic and muscarinic receptor binding in mouse brain. Brain Res 194:443-453.

Richclson E, Dininetz-Romero S (1977): Blockade by psychotropic drugs on the muscarinic acetylcholine receptor in cultured nerve cells. Biol Psychiatry 12:771-785.

Sitaram N, Moore AM, Gillin JC (1979): Scopolamine-induced muscarinic super-sensitivity in nomal man: Changes in sleep. Psychiatry Res 1:17-22.

Snyder SH, Yamamura HI (1977): Antidepressants and the muscarinic acetylcholine receptor. Arch Gen Psychiatry 34:236-239.

Szabadi P, Baszner P, Bradshaw CM (1980): The peripheral anticholinergic activity of tricyclic antidepressants: Comparison of amitriptyline and desipramine in human volunteers. $\mathrm{Br} J \mathrm{Psy}$ chiatry 137:433-439.

Tollefson GD, Senogles SE, Frey WH, et al (1982): A comparison of peripheral and central human muscarinic cholinergic receptor affinities for psychotropic drugs. Biol Psychiatry 17:555-567. 